\title{
CASE REPORT \\ BIDIRECTIONAL GLENN SHUNT AND REPAIR OF TOTAL ANOMALOUS PULMONARY VENOUS CONNECTION IN A 3 YEARS OLD CHILD WITH HETEROTAXY SYNDROME: A CASE REPORT
}

\author{
Shahyad Salehi-ardebili' ${ }^{1}$, Mohammad Radvar ${ }^{2}$, Behnam Askari ${ }^{1}$ \\ ${ }^{1}$ Seyed-al-Shohada Heart Center Shahrivar Street, Urmia University of Medical Sciences, Urmia, Iran, ${ }^{2}$ Shahid Motahari Hospital, \\ Kashani Street, Urmia University of Medical Sciences, Urmia, Iran
}

\begin{abstract}
Right Atrial Isomerism (RAI) and total anomalous pulmonary venous connection (TAPVC) is a rare condition with very high mortality in neonatal period, but outcomes may be better in older children. A cyanotic 3 years old boy with dyspnea and growth retardation diagnosed with RAI and supracardiac type of TAPVC undergone a successful repair of TAPVC and simultaneous Glenn shunt. Older patients with RAI may be a distinct, more suitable group for surgical repair.

Keywords: total anomalous pulmonary venous connection, heterotaxy, single ventricle, right atrial isomerism

Citation: Salehi-ardebili S, Radvar M, Askari B. Bidirectional Glenn Shunt and Repair of Total Anomalous Pulmonary Venous Connection in a 3 Years Old Child with Heterotaxy Syndrome: A Case Report. Pak Heart J. 2021;54(03):273-274. DOI: https://doi.org/10.47144/phj.v54i3.2165
\end{abstract}

\section{INTRODUCTION}

Heterotaxy syndrome also known as isomerism can be defined as a deviation from normal arrangement of thoraco-abdominal organs across the midline. The condition is rare (one in 10000 newborns) and very lethal particularly in neonatal period due to universal association with complex congenital heart diseases (CHD). There are two subtypes of Heterotaxy, Right Atrial Isomerism (RAI) which is far more prevalent with much higher rate of complex cardiac defects and left Atrial Isomerism (LAI).

Outcomes of surgical repair in cases with single ventricle physiology have been significantly improved but the results for those with single ventricle and TAPVC remain poor.

We describe a 3-year-old patient with RAI who underwent simultaneous repair of TAPVC and bidirectional Glenn shunt.

\section{CASE REPORT}

A 3 years old child (weight $11 \mathrm{~kg}$, height of $89 \mathrm{~cm}$ ) presented to us with cyanosis, mild dyspnea on exertion and growth retardation. His vital signs were within normal ranges except from moderate tachycardia. His past medical history was unremarkable except for a history of right inguinal hernia surgery. Echocardiography showed dextrocardia, single ventricle, severe pulmonary stenosis and supracardiac type TAPVC. Angiography showed left sided inferior vena cava (IVC) and superior vena cava (SVC), severely dilated SVC and innominate vein, supracardiac type TAPVC, small rudimentary right ventricle (which later at operation proved to be left ventricle) and severe valvar pulmonary stenosis (Figure 1,2).

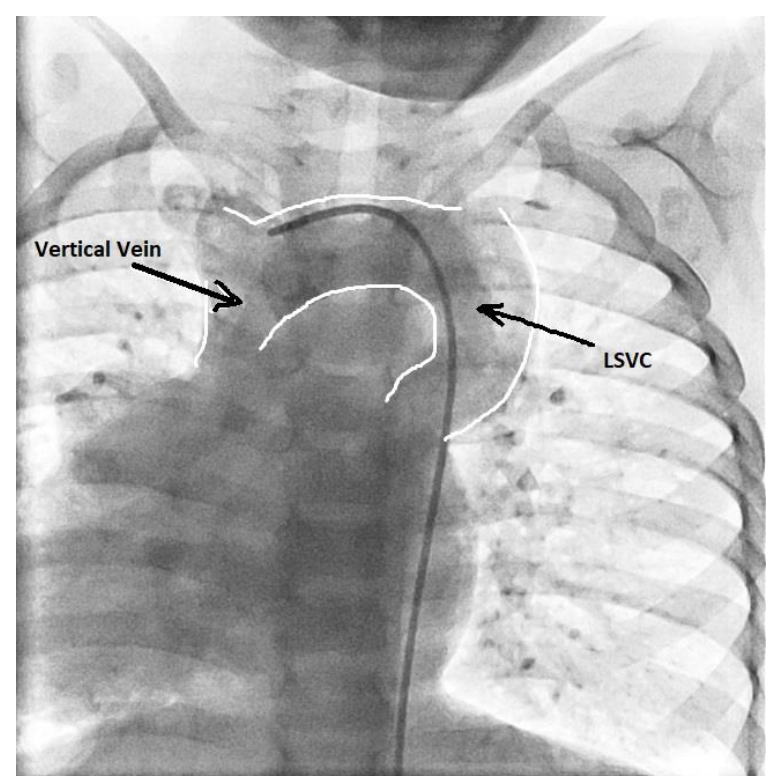

Figure 1: Angiography showing Dextrocardia, vertical vein and left $S V C$

Systemic arterial saturation was $80 \%$. Patient's Hematocrit was $46 \%$. The operation was performed through median sternotomy, with the surgeon standing at the left side of the Operating table (to facilitate the exposure for dextrocardia). High cannulation of SVC was done. Left ventricle and atrium was hypoplastic, and there was a common atrioventricular valve. TAPVC was approached through posterior wall of atrium and direct anastomosis between common chamber and atrium was done. Vertical vein was ligated and left SVC 
was anastomosed end to side to the pulmonary artery. The patient was easily separated from cardiopulmonary bypass (CPB) with low doses of Dopamine and Milrinone. Pulmonary artery pressure was measured at the conclusion of the operation which was $12-13 \mathrm{mmHg}$. CPB time and aortic cross clamp time was 224 and 88 minutes respectively. Length of hospital stay was 12 days.

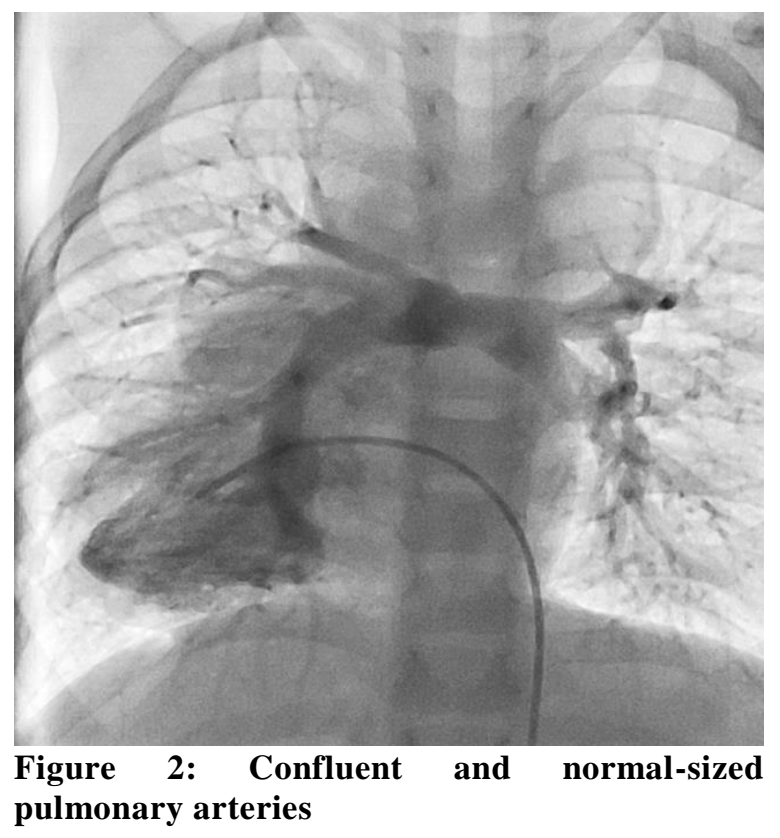

\section{DISCUSSION}

There is a high association of heterotaxy and TAPVC. Isomerism is seen in $30 \%-40 \%$ of patients with TAPVC and TAPVC is present in more $60 \%$ of the cases with Heterotaxy. ${ }^{1,2}$ RAI or LAI can be best diagnosed by bronchial anatomy. The bronchial length ratio of $<1.5$ indicates atrial isomerism while ratio $>2$ indicates lateralization. ${ }^{3}$ Pulmonary stenosis or atresia is almost a constant feature of these syndrome and it is seen in up to $97 \%$ of the patients. ${ }^{1,2}$

RAI is an independent risk factor for mortality and morbidity, responsible factors may include higher rate of infection due to associated asplenia, arrhythmia and atrioventricular valve regurgitation. ${ }^{4}$

There are evidences for better prognosis of RAI in pediatric patients older than 3 year-olds. The cause may be multifactorial including lower prevalence of deteriorating factors such as pulmonary vein obstruction, common atrioventricular valve, systemic outflow stenosis and single superior vena cava in older children. ${ }^{5}$

Best results are achieved in cases in whom TAPVC can be repaired at the time of BDG shunt. These, are the cases without pulmonary vein obstruction, which otherwise would necessitate early surgery in neonatal period when BDG shunt is not possible. In Hoashi series, 11 of 18 patients who had simultaneous repair of TAPVC and Glenn shunt survived to Fontan completion while only 2 of 25 patients who had repair of TAPVC before Glenn shunt did so. The later cases were those who had pulmonary vein obstruction, which could not be stented. ${ }^{2}$

In summary, regarding the published articles as well as our case, the children older than 3 year-olds with heterotaxy syndrome can be seen as a distinct category with much more favourable physiologic and anatomic characteristics that make them more suitable for surgical repair with better survival.

\section{AUTHORS' CONTRIBUTION}

SS: Concept and design, data acquisition, interpretation, drafting, final approval, and agree to be accountable for all aspects of the work. MR, BA: Data acquisition, interpretation, drafting, final approval and agree to be accountable for all aspects of the work.

Conflict of interest: Authors declared no conflict of interest.

\section{REFERENCES}

1. Nakayama Y, Hiramatsu T, Iwata Y, Okamura T, Konuma T, Matsumura G, et al. Surgical Results for Functional Univentricular Heart With Total Anomalous Pulmonary Venous Connection Over a 25-Year Experience. Ann Thorac Surg. 2011;93(2):60613.

2. Hoashia T, Kagisaki K, Oda T, Kitano M, Kurosaki K, Shiraishi I, et al. Long-term results of treatments for functional single ventricle associated with extracardiac type total anomalous pulmonary venous connection. Eur J Cardio-thoracic Surg. 2013;43(5):96570 .

3. Yim D, Nagata H, Z. Lam CH, Grosse-Wortmann L, Seed M, Jaeggi E, et al. Disharmonious Patterns of Heterotaxy and Isomerism. How Often Are the Classic Patterns Breached? Circ Cardiovasc Imaging. 2018;11(2):e006917.

4. Sugano M, Murata M, Ide Y, Ito H, Kanno K, Imai K, et al. Midterm results and risk factors of functional single ventricles with extracardiac total anomalous pulmonary venous connection. Gen Thorac Cardiovasc Surg. 2019;67(11):941-8.

5. Yan S, Jianpeng W, Xin Q, Minghui Z, Li Zh and Hao w. Right atrial isomerism in children older than 3 years. Springer Plus. 2016;5:1372.

\section{Address for Correspondence:}

Dr. Behnam Askari, Seyed-al-Shohada Heart Center, 17 Shahrivar Street, Urmia University of Medical Sciences, Urmia, Iran.

Email: askaribehnam@ymail.com 